\title{
The energy-water nexus: deja-vu all over again?
}

\author{
Water supplies are at risk of drying up as the climate warms, but mitigating climate change \\ could mean shifting to water-intensive alternative energy sources. Brian Hoyle reports on this \\ overlooked link.
}

W ith US policymakers struggling to contemplate a future where oil pipelines sputter and water wells come up empty, panellists at the recently concluded American Association for the Advancement of Science meeting in Boston urged a rethink of the connection between these two crucial resources.

The link between energy and water, commonly called the energy-water nexus, was once a cornerstone of Project Independence, an initiative in the administration of Richard Nixon that aimed for domestic energy self-sufficiency. Intervening discoveries of domestic oil and less fractious relationships with global energy suppliers caused interest to wane, however, and the project was shelved.

Flash ahead to 2008, and concerns over climate change have thrust the energy-water issue back into the spotlight. The burgeoning global population's ever-increasing need for fresh water is at odds with a warming world that is already squeezing water availability in some regions. And things will only get worse, according to the 2007 report of the Intergovernmental Panel on Climate Change, as current watermanagement practices are unlikely to quell demands. At least in the US, the energy-water nexus is creeping back onto the national stage.

It's about time, according to Peter Gleick, director of the Pacific Institute for Studies in Development, Environment, and Security in Oakland, California, and a panel member at the Boston conference. "Energy and water are closely linked. We use a lot of water to produce energy, especially fossil fuel energy. And we use a lot of energy to produce water - for food, to treat water, to capture and treat wastewater", says Gleick. "Energy constraints are beginning to affect water policy, and water policy is

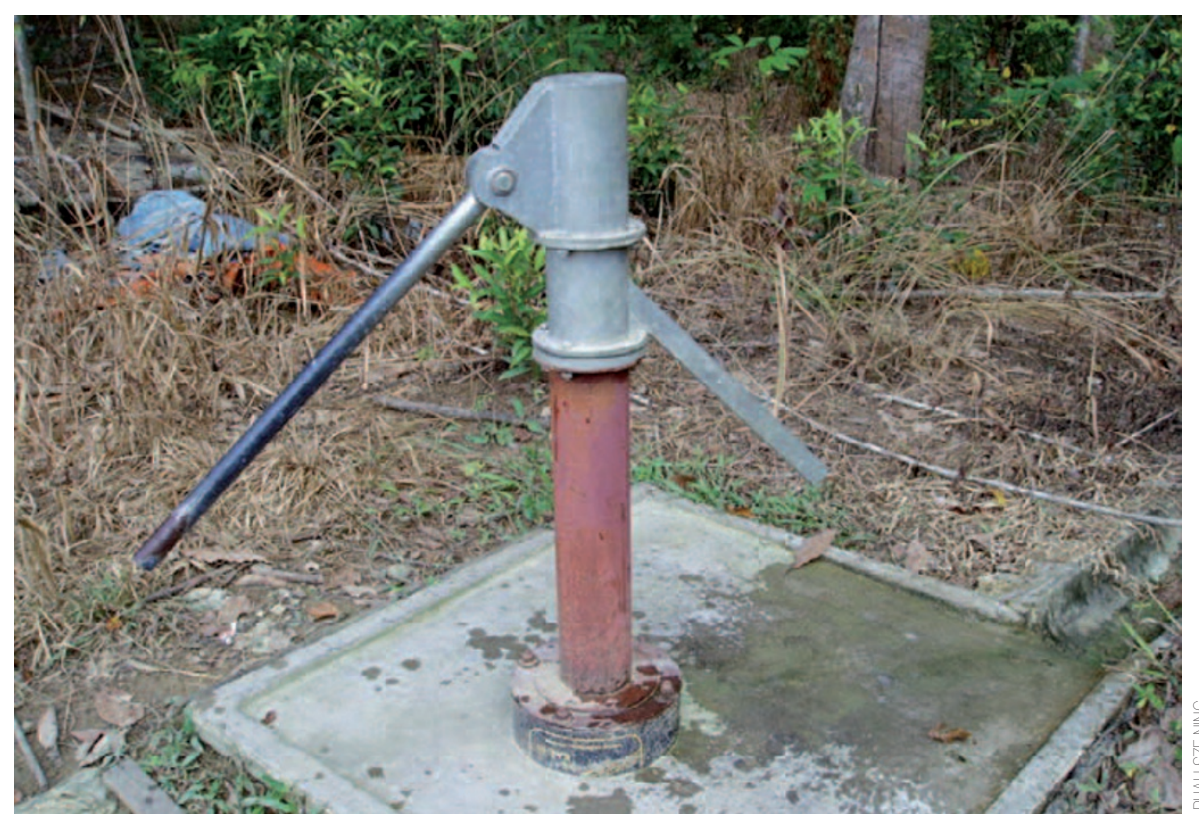

beginning to affect our energy choices. And yet, almost never do we integrate these two policies."

The US government has recently taken baby steps in this direction. In late 2006, the Department of Energy delivered a report to Congress on the interdependence of energy and water. This was complemented by the Energy-Water Roadmap, a series of workshops that solicited opinions from over 300 water managers and regulators on where the gaps lie in efforts to sustain future supplies of these precious resources. Now, the 2009 budget contains US $\$ 8$ million earmarked to help fund a Department of the Interior census of domestic water supplies - the first in 30 years.

Still, no single committee in Congress has jurisdiction over energy and water issues, which instead are cobbled together across more than two dozen House and Senate committees. This lack of cohesion extends to the state and local levels, where it has facilitated rivalry between neighbours over access to resources. Witness the Georgia legislature, which recently introduced an ill-fated bill to bump the state border further north, in an attempt to tap into the Tennessee River.

On another front, the US administration's recent biofuel zeal has overlooked the extensive irrigation required for those waving fields of midwest grain that supply the ethanol. Add the water used in processing to the irrigation supply, and at least 40 gallons go into every mile travelled by an ethanol-powered vehicle, according to Michael Webber of the Center for International Energy and Environmental Policy, University of Texas-Austin. 
Gas-electric hybrid vehicles fare little better, because electricity production is also a heavy water user. Webber figures that replacing all gasoline-powered vehicles with electric vehicles would require 17 times more water, nearly 11 gallons per mile, compared with the 0.6 gallons of water per mile it takes to power today's gas-guzzlers. Hydrogen power is even more water intensive, as energy is generated by electrolysis.
"We need to move from our old way of thinking - miles per gallon — to gallons of water per mile," says Webber.

"There are tradeoffs between energy and water," says Gleick. "It may be... that an increase in water use for certain kinds of fuels is a good thing if you're reducing greenhouse gas emissions and dependency on oil. Understanding the relative numbers in terms of water use and greenhouse gas emissions is part of the dynamic that all of us need to engage in. It's the first step, and I don't think that has happened."

Published online: 13 March 2008

doi:10.1038/climate.2008.22

Brian Hoyle is a freelance science writer and editor based in Nova Scotia, Canada.

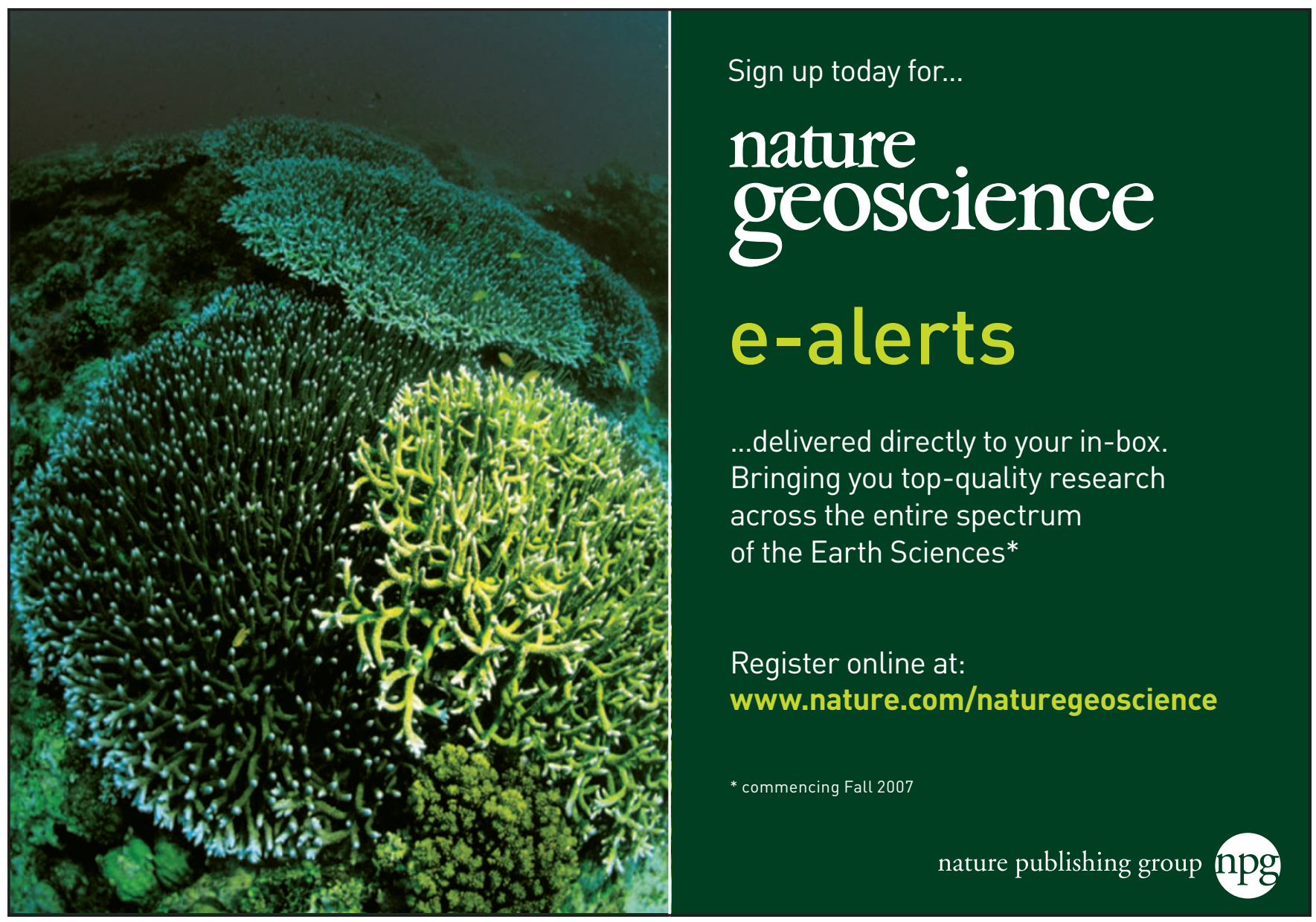

